\title{
A universidade pública em tempos neoliberais: comentários sobre o livro Universidade, cidade, cidadania
}

\author{
BERNARDO PARODI SVARTMAN I
}

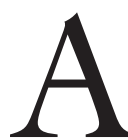

S RECENTES greves das universidades públicas brasileiras expuseram de forma contundente a grave crise de financiamento vivida por essas insti-

tuições. O cenário geral de contingenciamento de recursos, as tentativas de fechamento ou desligamento de serviços universitários, a reformulação de planos de carreira e até a elaboração de programas de demissão voluntária parecem ter anunciado em seu conjunto a irrupção abrupta, violenta e inadiável de uma encruzilhada histórica no caminho dessas instituições. No entanto, pelo menos em relação às universidades estaduais, a história da crise aponta dois problemas que influenciaram a situação e que merecem reflexão atenta: a expansão do sistema sem o equivalente aumento do repasse de recursos ao longo das duas últimas décadas e a falta de participação da comunidade acadêmica na definição e planejamento dos gastos, situação que caracteriza a administração universitária há várias gestões. ${ }^{1}$ A crise atual poderia então ensejar o contexto para um debate profundo sobre a democratização da universidade e sobre a afirmação da autonomia universitária no momento de forte tendência de privatização do público; no entanto, o que presenciamos foi uma forte restrição dos termos do debate: em muitos casos, o poder público, a grande mídia e as próprias gestões universitárias apresentaram a "modernização da universidade" como a única forma razoável de enfrentar a situação, expressão geralmente utilizada para justificar as inciativas cada vez mais numerosas de aproximação ao mercado, de privatização de atividades e serviços universitários e de precarização das condições de trabalho no interior da universidade. Isso nos permite pensar que as discussões e as ações tomadas, na forma como têm sido conduzidas pelas gestões universitárias e pelo poder público, parecem escamotear intencionalmente o fato de que a atual crise envolve uma disputa sobre o papel social da Universidade Pública e sua forma de inserção no tempo histórico, ou seja, sobre sua função pedagógica e política.

Essa breve evocação de alguns embates ocorridos em 2014 e 2015 teve como objetivo salientar a importância da análise dos fatores históricos, sociais e políticos na compreensão das tensões e transformações da Universidade Pública 
em nosso país. Nesse sentido, o livro do professor Franklin Leopoldo e Silva, intitulado Universidade, cidade, cidadania, apresenta uma contribuição essencial ao debate sobre o tema, e essa importância se expressa, entre outros fatores, em sua crescente atualidade. No seu conjunto, o livro discute a história da Universidade Pública e da educação universitária em nosso país, analisando a trama social e política envolvida na transformação de seu papel e de suas principais características ao longo do tempo. O livro apresenta o grande mérito de reunir em uma mesma visada a pesquisa histórica de seu objeto, uma sólida interpretação dessa pesquisa a partir da perspectiva da Teoria Crítica e o testemunho do próprio autor, relação bem estabelecida entre elementos capazes de oferecer ao leitor uma profunda concretude e densidade às reflexões apresentadas. Em relação a esse ponto, é possível antecipar que o entrelaçamento entre forma e conteúdo da reflexão presente no livro aponta caminhos de resistência às deformações da produção acadêmica decorrentes das pressões ligadas à reorganização contemporânea do trabalho docente.

Um dos objetivos que perpassam o conjunto dos capítulos é analisar historicamente as tensões e contradições presentes tanto no interior da universidade como em sua relação com a sociedade, observando nessa análise que há uma "[...] coincidência histórica entre o processo de recalque das contradições e o movimento de dissolução da Universidade como instituição política atuante no espaço público" (Leopoldo e Silva, 2014, p.99). No contexto de crescente mercantilização do ensino e da produção acadêmica, a adaptação da Universidade ao liberalismo tecnocrático atual diminui cada vez mais seu campo de autonomia e a possibilidade de desenvolvimento do pensamento crítico, vinculando de maneira cada vez mais imediata a universidade à tarefa de aprimorar e desenvolver as forças produtivas e a coesão social. Observa-se nesse processo uma redução do sentido da autarquia universitária: se antes essa noção estava ligada a uma indissociabilidade entre meios e fins e a uma relação mediatizada de atendimento de necessidades sociais, agora a adaptação e o atendimento dessas necessidades devem ocorrer de maneira imediata. Essa ideia pode ser entendida no contexto do livro como a progressiva destruição da Universidade como Instituição Pública para permitir o surgimento e a consolidação do modelo da Universidade como Organização Social, apoiada nos princípios de uma administração tecnocrática e eficiente, encontrada nas diversas formas atuais de privatização do público.

O primeiro ensaio, intitulado "A experiência universitária entre dois liberalismos", contextualiza historicamente o projeto liberal ilustrado de fundação da Universidade de São Paulo, para em seguida analisar o entrecruzamento entre a dimensão educacional e política do projeto, suas contradições de origem e como elas se desdobraram no diálogo com cada período histórico. Ao iluminar com profundidade a trajetória dessas contradições, expõe de forma articulada a história e a crise da instituição universitária em nosso país, examinando com 
rigor a seguinte tese: se o projeto dos liberais ilustrados envolvia a contradição de se contrapor ao poder das oligarquias pela preparação dos futuros dirigentes políticos do país, que seriam formados na nova universidade a partir dos valores da racionalidade moderna e republicana, ao mesmo tempo a participação em uma fatia do governo de 1932 e a visão implícita de sociedade e estado deixavam as marcas do autoritarismo político no projeto. Essa ambiguidade da posição política dos fundadores se refletiu principalmente na forma pela qual o poder de classe aparecia travestido em interesse geral, justificando a repressão ao espírito crítico radical que se formaria posteriormente na universidade. Essa contradição não deixou de se refletir na própria instituição: a necessidade de contestação da situação do ensino superior até o momento (praticamente reduzido à função de conferir distinção a uma elite no interior de uma sociedade estamental) e a intenção de estimular uma formação desinteressada, uma educação que não se restringisse à manutenção de interesses políticos imediatos e à formação técnico-profissional permitiram que a criatura pudesse se desenvolver inicialmente com uma margem de liberdade na qual o resultado não correspondeu inteiramente ao desejo dos fundadores. Esse fato se revelou no perfil crítico de pesquisa e ensino encontrado principalmente na Faculdade de Filosofia, Ciências e Letras, espinha dorsal do projeto da nova Universidade. No entanto, como aponta a ideia de "contradição de origem" presente no texto, não foram poucas as iniciativas presentes desde o início para barrar a radicalidade do projeto no interior mesmo da universidade, como revelou a disputa pelo controle do conselho universitário travada pelas faculdades tradicionais e as representantes do novo projeto. A transferência da faculdade para os barracões da cidade universitária logo após o conflito na rua Maria Antônia no ano de 1968 também demonstrou a intenção de isolamento da faculdade em relação à sua participação na vida política da cidade e o objetivo maior de controle de seu potencial subversivo.

Essa contradição de origem, que colocava a universidade simultaneamente dentro e fora de seu tempo, transforma-se à medida que o contexto econômico e político se altera. Nessa trajetória até o tempo atual, dois momentos merecem destaque por sinalizarem com mais força a progressiva redução da contradição e da dialética entre adaptação e contestação frente ao seu tempo histórico, abrindo cada vez mais espaço a uma universidade unidimensional, parafraseando a expressão de Marcuse: a reforma universitária ocorrida no período da ditadura civil-militar e posteriormente as reformas sintonizadas com o fortalecimento do neoliberalismo no período da Nova República. Na reforma universitária ocorrida durante o período ditatorial, tanto no nível estadual como federal, já se observava a aplicação das diretrizes formuladas no acordo MEC-Usaid: "O máximo de rendimento com a menor inversão", demonstrando claramente a intenção de reduzir o ensino universitário à formação de mão de obra de acordo com as exigências de mercado e da divisão internacional do trabalho, elevando com essa premissa o economista à posição de especialista na gestão universitária. 
Esse quadro não foi fundamentalmente alterado no período pós-ditadura, mas desenvolveu-se sob a forma da racionalidade tecnocrática que foi incorporada e desenvolvida pela própria gestão acadêmica.

O livro aborda a partir desse ponto uma questão essencial para nossos dias: como compreender o fato de que a transição para a democracia formal não foi capaz de reverter esse quadro? Os relatórios produzidos nos dois momentos históricos e que apoiaram as respectivas mudanças possuíam aspectos reveladores em comum: foram conduzidos por um pequeno grupo de "especialistas", sem incentivar a participação efetiva da comunidade; tampouco fizeram um trabalho de elaborar a história e a experiência acumulada da universidade, antes impuseram seus projetos a partir de uma análise a-histórica da conjuntura institucional e política mais ampla. A possibilidade de uma "refundação institucional" após o período ditatorial não ocorreu, "porque a implementação de um projeto tecnoburocrático de universidade organizacional, em ritmo acelerado, ultrapassou definitivamente qualquer possibilidade de reorganização política do espaço público acadêmico" (Leopoldo e Silva, 2014, p.110). O que ocorreu foi o desenvolvimento da dissolução do espaço público universitário e a elaboração de um projeto marcado por uma "modernização politicamente regressiva". Uma das estratégias perversas utilizadas para consolidar essa progressiva consolidação de uma universidade alinhada às novas exigências de mercado foi a divisão entre os professores "competentes" e os "improdutivos", promovendo uma estigmatização daqueles resistentes à "universidade do conhecimento" e aos "novos ares da modernização", e dessa forma, promovendo uma desqualificação pública dos opositores.

Compreender a mediação da totalidade social nessas transformações torna-se um elemento fundamental da reflexão sobre as dificuldades enfrentadas pela Universidade Pública atualmente. Esse é um dos eixos que articulam o conjunto dos capítulos e que é abordado ao longo do livro nas suas diversas manifestações e nos seus diferentes níveis de determinação estrutural. Há um fato importante identificado ao longo do livro em relação às transformações do sentido social da produção acadêmica e da organização do trabalho docente: o desenvolvimento da ideologia da competência como um elemento intrinsicamente ligado à redução da contradição interna na universidade e à destruição da memória da instituição. Se o projeto inicial tinha como objetivo preparar as futuras elites dirigentes, a noção de competência era o elemento responsável por ampliar as chances de acesso da população a esse estrato, garantindo dessa forma não exatamente a democratização do ensino e do exercício do poder político, mas uma certa mobilidade social para o conjunto e a garantia de rodízio que impediria a consolidação de uma casta governante. O liberalismo tecnocrático imprimiu gradativamente novos sentidos ao termo: competência se transformou em um novo modelo de recrutamento, organização e avaliação do trabalho que permite a desmoralização dos opositores e a destruição do espaço político institucional. 
Já é possível encontrar literatura abundante sobre esse elemento constituinte da reestruturação produtiva contemporânea: foi uma importante estratégia para facilitar e legitimar a destruição da resistência dos trabalhadores fora e dentro dos locais de trabalho, além de permitir a imposição de um novo nível de racionalização do trabalho (Antunes, 1999; Durand, 2003; Mello e Silva, 2004).

Essa importante intuição presente no livro ajuda a compreender as incríveis afinidades entres as transformações na organização do trabalho no setor industrial e as ocorridas recentemente dentro da Universidade Pública: as avaliações da produção docente desenvolvem-se em um caminho cada vez mais abstrato e quantitativo e, mesmo quando se fala de avaliar não a quantidade mas o impacto da produção acadêmica, busca-se com isso a redução do sentido da produção acadêmica a métricas cada vez mais controladas; os programas de pós-graduação se assemelham cada vez mais às células de produção industrial (Svartman; Crochík; Massola, 2015), onde as metas são impostas de forma heterônoma e os trabalhadores passam a controlar e até mesmo excluir os colegas que não mantenham o ritmo produtivo, diminuindo a visibilidade do conflito entre capital, poder de estado e trabalho também na academia; as avaliações e a premiação individual, assim como os controles de produção externos à instituição, incentivam a competição e diminuem a possibilidade de organização coletiva dos trabalhadores (a formação de grupos de pesquisa não significa superação desse problema, uma vez que devem enfrentar o mesmo cenário de competição, agora reproduzido no nível de equipes e programas de pós-graduação). Os instrumentos de avaliação de desempenho configuram-se como um mecanismo poderoso de imposição da nova ordem: por meio deles, os que não se submetem são desmoralizados publicamente e apresentados como inimigos do "controle social" da atividade acadêmica, ao mesmo tempo em que seus resultados permitem a consolidação de privilégios e poder àqueles que os controlam. No interior desse cenário, as associações de funcionários e docentes sofrem uma progressiva desligitimação pública como interlocutor no debate das transformações universitárias, tanto nos meios de comunicação como em parte dos órgãos dirigentes. Nesse sentido, a ideologia da competência promove uma homogeneização entre o ambiente de trabalho universitário e qualquer outro espaço de trabalho, entre seus resultados e a forma mercadoria de produção social, operando com isso a progressiva reificação do trabalho universitário: gradualmente somos conformados a pensar os resultados do trabalho universitário em termos de produtos e serviços que devem ser integrados ao sistema produtivo ou então a adotar o fetiche dos rankings como forma de avaliar a relevância da instituição.

A questão fundamental apresentada após essa profunda análise do desenvolvimento da racionalidade tecnocrática na universidade passa a ser a seguinte: como explicar que a própria comunidade acadêmica tenha incorporado esse modelo de universidade e parece desenvolvê-la como um princípio interno de seu funcionamento? Essa pergunta é de fundamental importância, pois aborda 
a forma pela qual a repressão do pensamento crítico foi incorporada pelo próprio conjunto da atividade universitária. A partir de uma análise das reflexões e depoimentos de autores que abordaram as consequências do horror da ditadura sobre a universidade, o livro nos permite pensar que o momento da barbárie interiorizou pelo medo a autocensura e a perda de referências políticas e institucionais na convivência acadêmica. A repressão política buscou operar a ruptura da transmissão da memória histórica da instituição. Posteriormente, com o fim do período ditatorial, o desenvolvimento da gestão tecnocrática do trabalho acadêmico aparecia naturalmente como a adaptação da universidade aos novos tempos. Como os inimigos políticos pareciam ter desaparecido, os que se opunham ao desenvolvimento do projeto liberal tecnocrático foram taxados como desajustados, defendendo apenas interesses corporativistas. A ditadura fez o tratamento de choque, a partir do terror, necessário para a incorporação de uma lógica unidimensional de adaptação que, por ter sido posteriormente absorvida pela gestão acadêmica, ganha a aparência de autonomia. O ponto de semelhança apresentado entre os relatórios Ferri e o relatório Geres, que apoiaram respectivamente reformas no período ditatorial e na redemocratização, serve como exemplo para demonstrar a continuidade e ao mesmo tempo a fratura histórica. Nesse sentido, é possível supor a partir da leitura do livro e de nossa experiência atual que a atividade acadêmica passe hoje no seu conjunto por um processo de dessublimação repressiva: a possibilidade de sublimação ligada à atividade intelectual encontra-se cada vez mais aprisionada pelo enquadramento na eficiência produtiva, a adaptação à quantidade e às métricas, à forma preestabelecida pelas avaliações dos programas e dos periódicos. O prazer de se obter boas avaliações e recursos se sobrepõe ao prazer da investigação e da reflexão. Grande parte da motivação para a investigação livre passa a ser contida e dirigida para o bom funcionamento do sistema, gerando, como já havia observado Marcuse (1993), o fato de que a dessublimação controlada fortalece a coesão e a adesão ao sistema. Esse fato também permite compreender algumas tendências contemporâneas do trabalho universitário: simpósios e eventos já começaram a revelar formas de sofrimento e adoecimento entre os professores semelhantes às categorias profissionais que foram mais atingidas pela reestruturação produtiva (bancários, trabalhadores de escritório), com especial destaque para as lesões por esforços repetitivos (LER/Dort), problemas de sono, crises de angústia e depressões, fato que evidencia a redução do sentido das atividades acadêmicas para os próprios docentes. Como já havia afirmado Dejours (2008), as avaliações representam uma das principais fontes de sofrimento e mal-estar na atualidade: longe de estabelecer formas equitativas de reflexão e aprimoramento das contribuições feitas por cada trabalhador, algo que poderia inserir as avaliações numa dinâmica de reconhecimento nas instituições, refinaram e individualizaram formas de medição e de controle sobre o trabalho. As avaliações de desempenho, ao enfatizar resultados mensuráveis, tendem a deixar na invisibilidade e sem reconhecimento público boa parte do trabalho realizado: no caso universitário, isso tende a di- 
minuir o espaço para assimilação e apresentação de momentos essenciais da pesquisa e da reflexão, como as incertezas, as hesitações e os fracassos. Em muitos casos, as consequências da disseminação das formas de avaliação que têm por base a medição de desempenho é a destinação individual do sofrimento, situação que o potencializa, uma vez que as humilhações encontram cada vez menos formas de resposta em coletivos organizados no próprio ambiente de trabalho. Outra hipótese que poderíamos levantar é que essa situação parece determinar intrinsicamente o crescimento do que se convencionou chamar de "má conduta científica”, expressa nas retratações de pesquisadores, parecendo evidenciar que as novas práticas de gestão estimulam condutas antiéticas, já que as avaliações privilegiam os resultados e dissociam as relações orgânicas entre meios e fins. ${ }^{2}$

Outro aspecto importante da análise e que se apresenta como um eixo articulador dos capítulos é a discussão das consequências da universidade tecnocrática para o trabalho de docência e para a formação dos alunos. A produção do conhecimento agora voltada restritivamente para o desenvolvimento das forças produtivas ou para o fortalecimento e coesão do funcionamento social prepara a imposição do existente, faz do conhecimento produzido e transmitido uma das dimensões atuais de preparação do hiper-realismo. Essa formação reduzida à sua dimensão técnica e operacional diminuiu o campo de uma educação crítica. A mera adaptação significa o aprisionamento ao presente, e nesse caso, a formação não mais possibilita a elaboração do passado e possibilidade de escolha de novos horizontes futuros. Observa-se na universidade tecnocrática uma perpetuação do desenraizamento contemporâneo na forma da produção e transmissão do conhecimento. A passagem da instituição para o modelo de organização social impôs uma série de consequências para a convivência acadêmica que também tendem a reforçar essa tendência: o modelo de gestão, a submissão aos órgãos de fomento e o fortalecimento das fundações tendem a destruir os espaços de agremiação política interna, e com isso os professores se desligam cada vez mais da instituição, tornando a universidade um agregado de indivíduos. Há um profundo mal-estar na convivência comunitária identificado pelos alunos e trabalhadores da universidade, difícil de ser compreendido e que se expressa de múltiplas formas: a competição se impôs como padrão de convivência e a sobrecarga de trabalho diminuiu o tempo que os professores dedicam ao ensino e aos alunos. Em nome da eficiência organizacional, aumenta a distância entre os representantes das diversas categorias da comunidade acadêmica e os verdadeiros centros de poder.

Ao final do livro, a discussão sobre o futuro da universidade aborda a visão de história implícita nos projetos que buscam justificar a universidade tecnocrática como o único modelo possível: em toda forma ideológica de justificar adesão ao existente, a imaginação do futuro é uma simples forma de corroborar a manutenção e aperfeiçoamento do presente e, justamente por isso, nega à universidade seu papel de agente histórico. Como já havia notado em outro 
belíssimo ensaio sobre o descontrole do tempo histórico, o progresso, elemento pelo qual se justifica o estado atual de coisas, se apresenta hoje "como uma força sempre presente em nossas vidas, mas cujo sentido já nos é difícil decifrar" (Leopoldo e Silva, 2008, p.155). A experiência histórica atual encontra-se profundamente marcada pela contingência e pela fatalidade, sofre as marcas do desenraizamento, porque a experiência de participação política continua sendo atacada pelo poder da mercantilização das relações sociais e a consequente dissolução do espaço público. Como afirmou o autor:

O desaparecimento do espaço comunitário e da intersubjetividade política configura o vazio que nos separa do valor que poderia conferir base sólida à dignidade humana. Trata-se de uma mutação que, vivida como ruptura, impede que a memória histórica venha em auxílio de uma possível recuperação da integridade da experiência. (Leopoldo e Silva, 2008, p.157)

A mediação da totalidade social pressiona a universidade a seguir os mesmos caminhos e a sofrer as mesmas rupturas. No momento de forte dissolução da intersubjetividade política também na universidade, no momento em que o mercado se afirma cada vez mais como valor universal no qual a pesquisa e o ensino devem inserir-se, no momento em que a própria instituição empenha-se em apagar sua história em nome de uma gestão "produtiva e eficiente", o livro do professor Franklin Leopoldo e Silva nos lembra a importância de recuperar a história dessa instituição a "contrapelo", parafraseando uma expressão de Benjamin (1994). Se a reificação é sempre um esquecimento, como afirmaram Horkheimer e Adorno (1985), relembrar e reelaborar a história da universidade pública torna-se um imperativo nos dias atuais: a articulação entre memória histórica e reflexão crítica poderá ajudar a romper o imperativo da mera adaptação ao existente, a recuperar esperanças e contradições que ficaram pelo caminho e, principalmente, impedir que a própria produção de conhecimento na Universidade se transforme em forma de destruição da crítica e preparação do hiper-realismo contemporâneo. Em tempos nos quais a universidade parece sucumbir ao imperativo da mera adaptação, o que o professor Franklin Leopoldo e Silva nos oferece com seu livro também é um convite a um trabalho coletivo de reelaboração de sua própria história, soprar as centelhas da tradição que ela ainda é capaz de sustentar, apoiado na convicção de que isso já representa uma das dimensões da crítica da experiência como resistência e formação possíveis.

\section{Notas}

1 Essas conclusões foram apresentadas em um dossiê organizado pela Adusp no ano de 2015, intitulado "Crise financeira ou crise de financiamento?", e se apoiam na análise de dados relativos ao aumento do número de vagas na graduação e pós-graduação e à criação e incorporação de novos campi a partir do final da década de noventa sem o proporcional aumento de repasse de recursos. Esse fato já havia levado o Cruesp a demandar, em documento redigido no ano de 2005, o aumento de repasse de verbas para 
a manutenção adequada das universidades. O documento está disponível em: <http:// www.adusp.org.br/files/cadernos/financUSP.pdf>.

2 Sobre a questão do aumento da "má conduta científica", é possível encontrar uma discussão recente sobre o assunto no artigo publicado pela agência Fapesp de notícias. Disponível em : <http://agencia.fapesp.br/ma_conduta_cientifica_e_um_problema_ global_afirma_pesquisador/19643/>.

\section{Referências}

ANTUNES, R. Os sentidos do trabalho: ensaio sobre a afirmação e negação do trabalho. São Paulo: Boitempo, 2002.

BENJAMIN, W. Magia e técnica, arte e politica: ensaios sobre literatura e história da cultura. São Paulo: Brasiliense, 1994.

DEJOURS, C. A avaliação do trabalho submetida à prova do real. São Paulo: Blucher, 2008 .

DURAND, J. P. A refundação do trabalho no fluxo tensionado. Tempo Social, v.15, n.1, p.139-58, 2003.

HORKHEIMER, M.; ADORNO, T. W. Dialética do esclarecimento. Rio de Janeiro: Jorge Zahar, 1985.

LEOPOLDO E SILVA, F. Descontrole do tempo histórico e banalização da experiência. In: NOVAES, A. (Org.) Mutações: ensaios sobre as novas configurações do mundo. São Paulo: Sesc - Agir, 2008. . Universidade, cidade, cidadania. São Paulo: Hedra, 2014.

MARCUSE, H. El hombre unidimensional. Barcelona: Planeta-De Agostini, 1993.

MELLO E SILVA, L. Trabalho em grupo e sociabilidade privada. São Paulo: Editora $34,2004$.

SVARTMAN, B. P.; CROCHÍK, J. L.; MASSOLA, G. M. A reestruturação produtiva universitária e suas consequências sobre a produção acadêmica. Psicologia USP, São Paulo, v.26, n.2, p.129-32, 2015.

Bernardo Parodi Svartman é professor do Departamento de Psicologia Social e do Trabalho, do Instituto de Psicologia da USP. @- bernardo@usp.br

Recebido em 15.2.2016 e aceito em 7.3.2016.

I Instituto de Psicologia, Universidade de São Paulo. São Paulo/ São Paulo, Brasil. 
